Archived version from NCDOCKS Institutional Repository http://libres.uncg.edu/ir/asu/

Bin, O., Poulter, B., Dumas, C., \& Whitehead, J. C. (2011). Measuring the Impact of Sea-Level Rise on Coastal Real Estate: A Hedonic Property Model Approach, Journal of Regional Science, 51(4):751-767. Publisher's version available from http://www.wiley.com/WileyCDA/Section/index.html (ISSN: 0022-4146) DOI: 10.1111/j.14679787.2010.00706.x

\title{
MEASURING THE IMPACT OF SEA-LEVEL RISE ON COASTAL REAL ESTATE: A HEDONIC PROPERTY MODEL APPROACH
}

\author{
Okmyung Bin, Ben Poulter, Christopher F. Dumas, John C. Whitehead
}

\begin{abstract}
This study estimates the impact of sea-level rise on coastal real estate in North Carolina using a unique integration of geospatial and hedonic property data. With rates of sealevel rise approximately double the global average, North Carolina has one of the most vulnerable coastlines in the United States. A range of modest sea-level rise scenarios based on the IPCC Fourth Assessment Report projections (2007) are considered for four counties of North Carolina-New Hanover, Dare, Carteret, and Bertie-which represent a cross-section of the state's coastline in geographical distribution and economic development. High-resolution topographic LIDAR (light detection and ranging) data are used to provide accurate inundation maps for the properties that will be at risk under six different sea-level rise scenarios. A simulation approach based on spatial hedonic models is used to provide consistent estimates of the property value losses. Considering just four coastal counties in North Carolina, the value of residential property loss without discounting in 2030 (2080) is estimated to be about $\$ 179$ (\$526) million for the mid-range sea-level rise scenarios. Low-lying and heavily developed areas in the northern coastline are comparatively more vulnerable to the effect of sea-level rise than the other areas.
\end{abstract}




\section{INTRODUCTION}

Sea level is rising along much of the U.S. coast and worldwide. During the last century, sea level along the Mid-Atlantic coast rose 12-15 centimeters $(\mathrm{cm})$ faster than the global average due to land subsidence. Higher temperatures are expected to further raise sea level in coastal zone by expanding ocean water and by melting mountain glaciers and large portions of Greenland and the Antarctic ice sheets. Recent research shows that the global sea level is expected to rise about 9-59 cm over the next century (Intergovernmental Panel on Climate Change (IPCC), 2007).

Coastal areas in the United States include some of the most developed areas in the nation and represent the nation's wealth of natural and economic resources. In 2003, approximately 153 million people (53 percent of the total population) lived in the nation's coastal fringe that makes up 17 percent of its contiguous land area (National Oceanic and Atmospheric Administration (NOAA), 2005). The 673 coastal counties have seen an increase of 33 million people since 1980 (NOAA, 2005). Population growth has been accompanied by unparalleled growth in property values. The value of coastal real estate has appreciated at an average 7 percent per year over the last 50 years. According to the Heinz Center (2000), a typical coastal property is worth from 8 percent to 45 percent more than an otherwise comparable inland property.

While population growth and coastal development produce numerous economic benefits, the relatively dense populations and valuable coastal properties are vulnerable to substantial risks associated with climate change and sea-level rise including coastal flooding, shoreline erosion, and storm damages. 1 The amount of developed property along the North Carolina coastline has steadily increased over the last several decades due to a strong preference for coastal locations. The number of building permits in Carolina Beach, North Carolina between 2001 and 2005 exceeds the number of permits issued over the previous 20 years, and the average selling price for residential properties in Wrightsville Beach, North Carolina has increased 420 percent since 2001 (Raleigh News \& Observer, "Beach Prices Ride Crest," 29 May 2005).2 Rapid development coupled with soaring property values brought greater vulnerability to rising sea level.

This study attempts to estimate the potential impact of sea-level rise on coastal real estate in four counties of North Carolina-New Hanover, Dare, Carteret, and Bertie- which represent a cross-section of the state's coastline in geographical distribution and economic development (Figure 1). Coastal North Carolina has been identified as one of the most vulnerable regions to climate change in the United States (Titus and Richman, 2001). The study area covers from high development to rural economies with shoreline dominated by estuarine to marine environments. Property parcel data are obtained from each county tax office, which maintains the assessed value and other structural characteristics of property. High-resolution topographic light detection and ranging (LIDAR) data are used to provide accurate inundation maps for all property that will be at risk under different sea-level rise scenarios. Adjusting for regional subsidence, a range of modest sea-level rise scenarios based on the IPCC Fourth Assessment Report projections (2007) are considered. Additional geospatial attributes are developed to describe the distance of a property to shoreline and property elevation and entered into a database of corresponding property values. Using the 
geospatial and property data, spatial autoregressive hedonic models are estimated to provide consistent estimates of the hedonic parameters, which will be used in the simulation models to estimate the impact of sea-level rise on coastal real estate.

The potential cost of sea-level rise has been included in the earlier measures of the economic damage estimates that global warming might impose on the United States (Cline, 1992; Titus, 1992). Separate estimates for the original cost of sea-level rise have

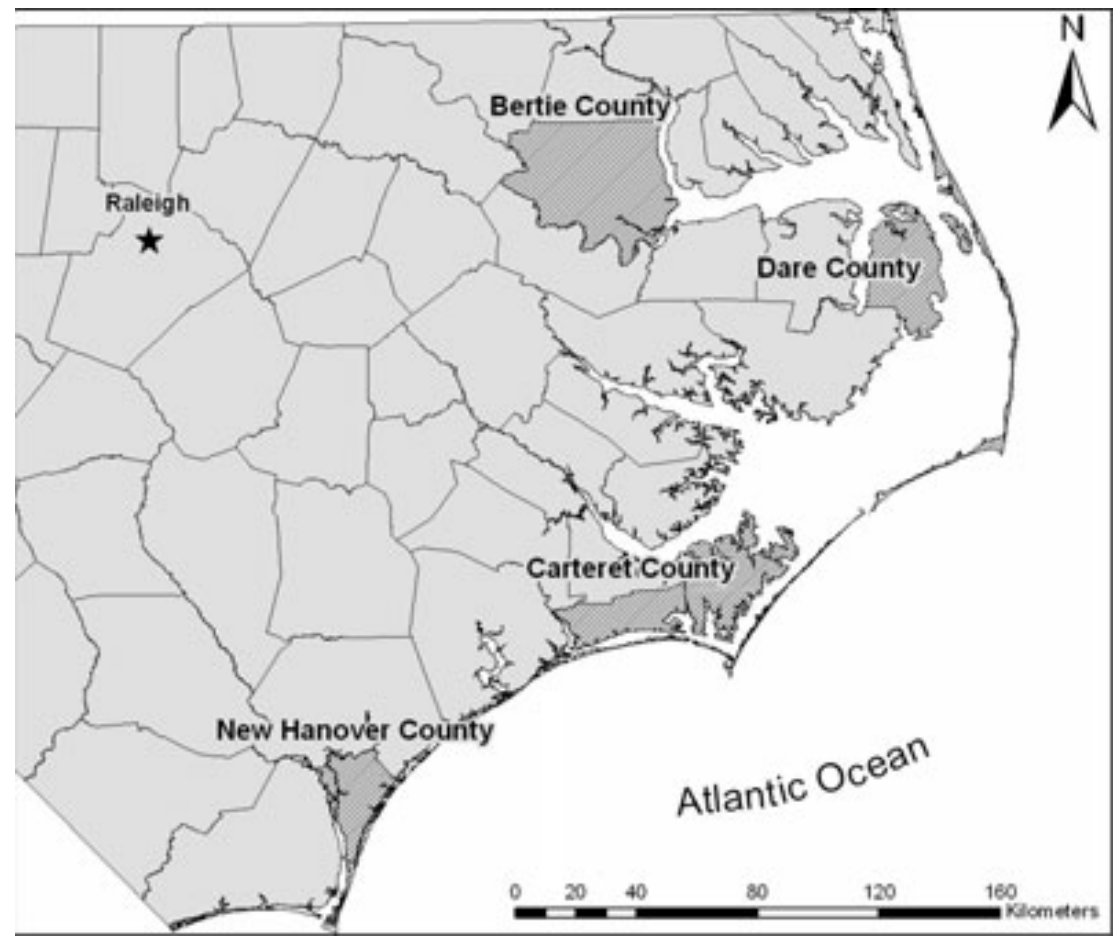

FIGURE 1: Location of NC Counties Analyzed for Property Impacts

been assessed, given its importance in assessing the potential damage of climate change. Since the work by Yohe et al. (1995) the literature on the cost of sea-level rise has grown, but the growth has been rather slow. Most of the recent additions to the literature estimate the annual inundation cost at a national or global scale (Darwin and Tol, 2001; Yohe et al., 1996; Yohe et al., 1999). Utilizing the estimated nationwide acreage losses for various sea-level rise scenarios and average property values, these studies provided the estimated annual losses for the entire U.S. coastline.

Estimates of the cost of sea-level rise at a regional or local level are important for planning a long-term policy response to the threat of sea-level rise. Yohe et al. (1995) provided a conceptual basis for estimating economic cost of sea-revel rise. They argued that the true cost of coastal inundation should be represented by the value of interior land as the costal amenities are transferred to more inland parcels. In their application to Charleston, South Carolina, they estimated the potential loss of land and structure value with aggregate property data. Adapting the methodology of Yohe et al. (1995), Parsons and Powell (2001) estimated the economic costs of beach retreat for Delaware over the next 50 years using a more disaggregated unit of observation than the previous studies in the literature. Using microlevel property transaction data, this study estimated 
the cost of beach retreat in Delaware in the next 50 years to be about $\$ 291$ million in present value (2000 USD).

West et al. (2001) and Michael (2007) further estimated not only the cost of inundation but also the cost of the increased storm surge flooding from sea-level rise. West et al. (2001) considered that sea-level rise may increase the vulnerability to storm damage by decreasing the distance between the shore and structures and by eroding protective coastal features. Using data from the National Flood Insurance Program (NFIP) and a hypothetical community, they estimated that the increase in storm damage attributable to sea-level rise is small although the total storm damage can be large. Focusing on more heavily developed communities on the Chesapeake Bay, Michael (2007) found that increased storm flood damage is much larger than the cost of inundation, suggesting that previous studies may be substantially underestimating the economic costs of sea-level rise in the United States. This measure is perhaps a more fundamental concept that will provide evidence on the economic vulnerability of coastal real estate to rising sea levels.

Such information should provide guidance in long-term development and planning decisions under sea-level rise. A formal benefit cost analysis of a climate change policy would compare the benefits of avoiding the consequences of climate change with the costs. One component of the benefits of climate change policy is the avoided inundation costs of sea-level rise. The objective of this study is to provide more evidence on the cost of sea-level rise, and to do so in a geographic region for which the cost has not been estimated. Our results indicate that the impacts of sea-level rise on coastal property values vary across different portions of the North Carolina coastline. The most significant loss is occurring in Dare County (northern), followed by Carteret (central), New Hanover (southern), and Bertie (rural) counties. Depending on the sealevel rise scenarios, the loss of residential property value in Dare County ranges between 1.24 percent and 9.45 percent of the total residential property value without discounting. The residential property value at risk in Carteret County ranges from 0.20 percent to 2.41 percent. New Hanover and Bertie counties show relatively small impacts with less than 1 percent loss in residential property value. Overall, the northern part of the North Carolina coastline is comparatively more vulnerable to the effect of sea-level rise than the southern part. Considering just four coastal counties in North Carolina, the value of residential property loss without discounting in 2030 (2080) is estimated to be about $\$ 179$ (\$526) million for the midrange sea-level rise scenarios. With a high sealevel rise scenario, the value of residential property loss in 2080 could be up to $\$ 1.2$ billion without discounting. The result of this study demonstrates that increased inundation and shoreline erosion associated with sea level rise may result in significant economic losses in coastal real estate in the absence of local mitigation and adaptation policy.

\section{STUDY AREA AND DATA}

North Carolina's coastal plain is one of several large terrestrial systems around the world threatened by rising sea levels (Moorhead and Brinson, 1995; Titus and Richman, 2001). Over $5,000 \mathrm{~km} 2$ of the land area is below 1 melevation, and rates of sea-level rise in this region are approximately double the global average due to local isostatic 
subsidence (Poulter and Halpin, 2008). In the northern region of the state, rates of sealevel rise are up to $0.4 \mathrm{~m}$ per century, decreasing somewhat to $0.3 \mathrm{~m}$ per century in the southern coastal region (Figure 2).3 Continued and projected sea-level rise is expected to significantly impact natural and human systems with global estimates anywhere between 0.3 and $1.1 \mathrm{~m}$ likely (Pfeffer et al., 2008).

Property parcel spatial and tabular attributes were acquired for four counties-

Bertie, Dare, Carteret, and New Hanover-representing a variety of geomorphic and economic resources. The centroid for each property parcel was calculated (restricting its location to within the tax parcel boundary) assuming that it represented average conditions within the property parcel (Figure 3). Oceanfront and estuarine-front properties were identified for all four counties for current sea level. Attributes were added to these property parcels indicating what type of shoreline position they currently occupy.

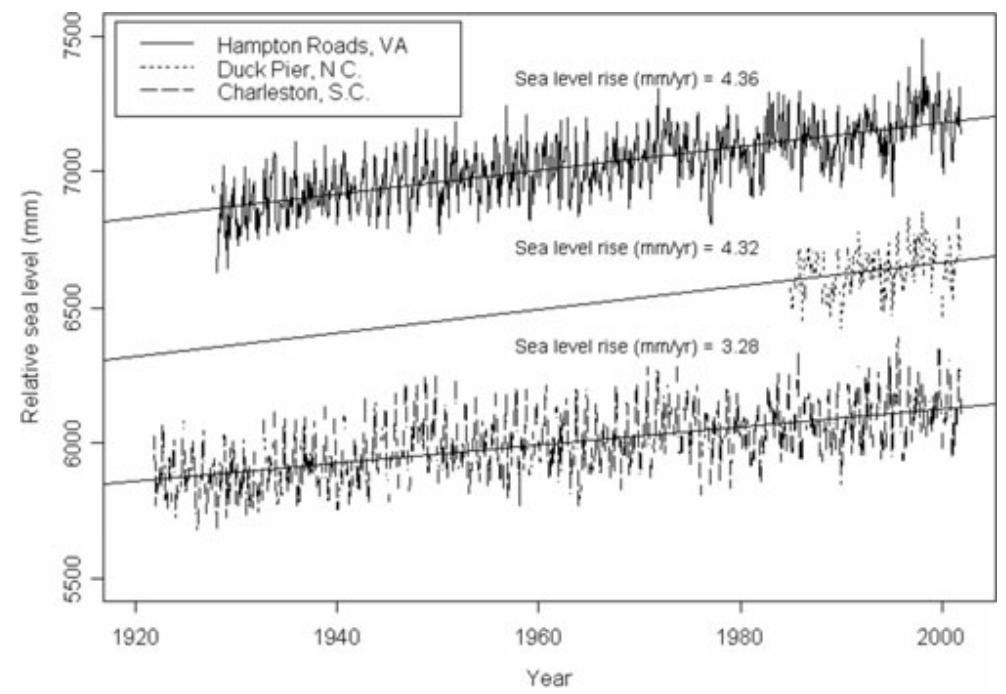

FIGURE 2: Observed Rates of Sea-Level Rise along the Southeast Coast.
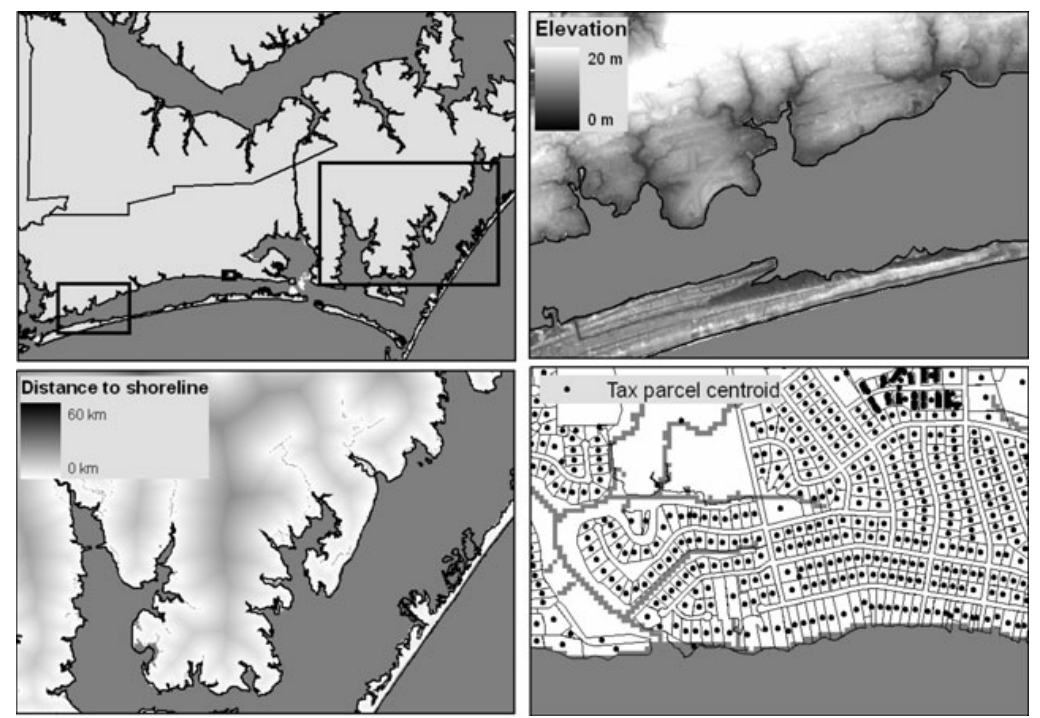

FIGURE 3: Examples of Data Sampling for Property Values for Carteret County (a), LIDAR Elevation Surface (b), Distance to Shoreline (c), and Tax Parcel Centroids (d). 
TABLE 1: Summary of Sea-Level Rise for the Low, Mid, and High Climate Change Scenarios

\begin{tabular}{lcc} 
Year & Scenario & $\begin{array}{c}\text { Projected Sea-Level Rise (SLR) } \\
\text { Measured in Meters }\end{array}$ \\
\hline 2030 & Low & 0.11 \\
& Mid & 0.16 \\
2080 & High & 0.21 \\
& Low & 0.26 \\
& Mid & 0.46 \\
& High & 0.81 \\
\hline
\end{tabular}

Note: Projected sea-level rise includes both eustatic and isostatic components.

Distance to shoreline was created for each inundation scenario. We used Euclidean distance to describe the proximity of a property parcel to the shoreline.

Property parcel centroids were then used to sample the seven distance inundation surfaces (current and six scenarios). Land elevation was sampled and assigned as an attribute to each property parcel using the centroid. The LIDAR-derived Digital Elevation Model (DEM) was used as the source of elevation measures. This DEM has had buildings systematically removed although there may still be errors that are greater than the average $\pm 0.25 \mathrm{~m}$. Therefore, it is most likely that the elevation values reported for property parcels in dense urban areas represent an overestimate for elevation. The six inundation grids representing the new shoreline-ocean interface following sea-level rise was sampled by the property parcel centroids. Attributes reflecting whether a property parcel was inundated were added to each parcel record for the impact analysis.

The parcel elevation could be represented in many ways, for example, mean, maximum, minimum, variance of elevation, etc. Centroids represent the geometric center of a polygon (i.e. parcel), taking into account of vertice locations and angles between edges, and not just the approximate middle of a polygon. They are representative of the overall polygon feature, measured at the scale of property units. The centroid approach is commonly used to represent spatial features of parcels as it reasonably represents the spatial variability of elevation within a parcel (McKenzie and Levendis, 2010) and is an efficient method for mapping parcel elevations over large landscapes where tens of thousands of parcels exist. Centroids represent the geometric center of a polygon (i.e. parcel), taking into account of vertice locations and angles between edges, and not just the approximate middle of a polygon. Here, we assume that the centroid elevation corresponds to the vulnerability of the physical building to inundation and damage from coastal impacts. The centroid elevation is not an indicator of the exact elevation of a building, which is only possible to assess via surveying techniques.

Six scenarios for future sea-level rise were developed from the recent IPCC report (2007). These scenarios were adjusted for regional subsidence that is geologically important in North Carolina (Tushingham and Peltier, 1991). Table 1 presents an 11 centimeters (cm) increase in sea level by 2030 (2030-Low), a 16-cm increase by 2030 (2030-Mid), a 21-cm increase by 2030 (2030-High), a 26-cm increase by 2080 (2080-Low), a 46-cm increase by 2080 (2080-Mid), and an 81-cm increase by 2080 (2080-High). Figure 4 provides inundation of coastal North Carolina with detailed 
examples for each of the counties investigated in this study. This particular example uses an $81-\mathrm{cm}$ increase in sea-level rise by 2080 including both eustatic and isostatic sea-level rise. Table 2 presents the summary statistics for data.

TABLE 2: Summary Statistics for the Hedonic Data

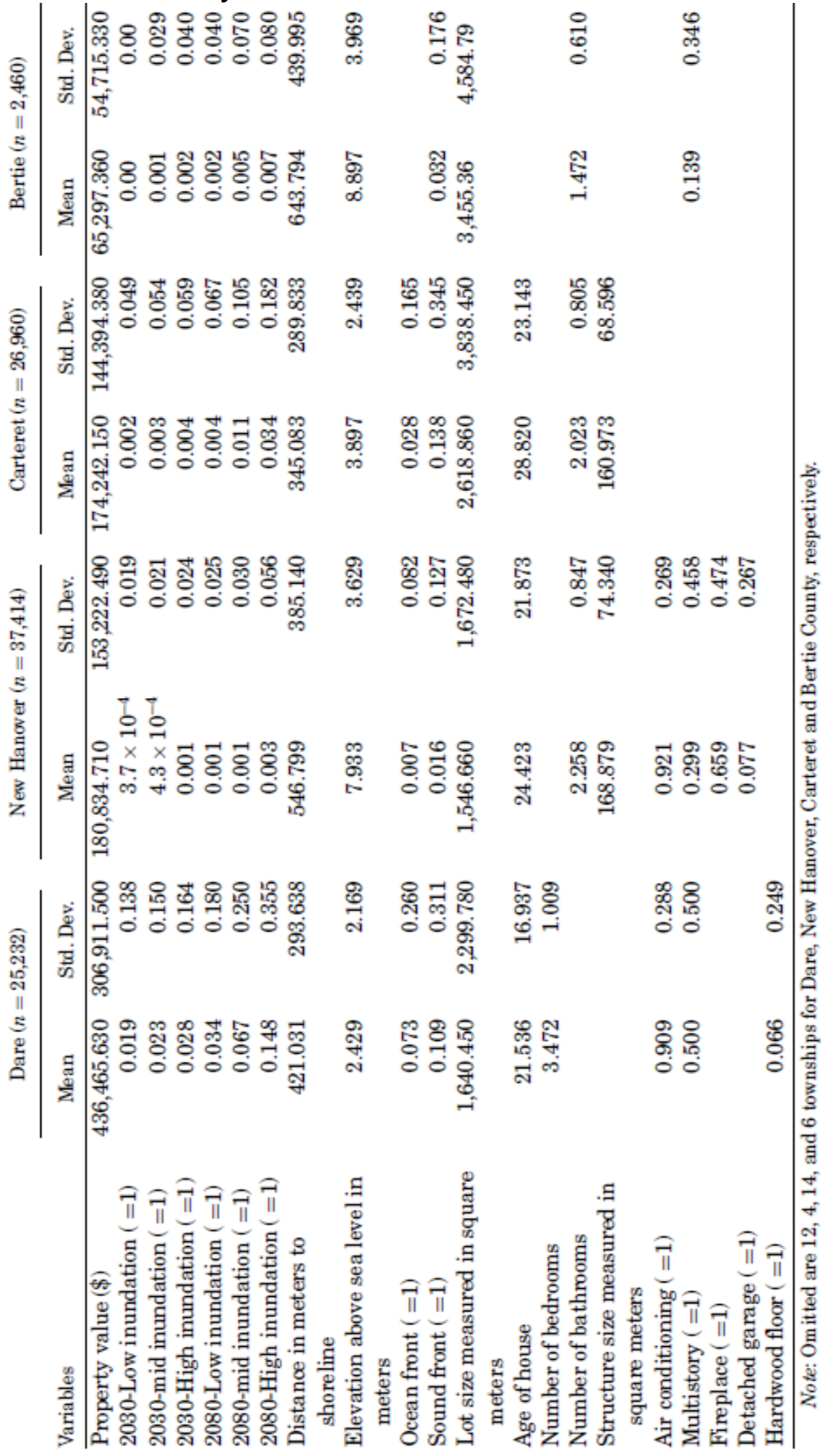




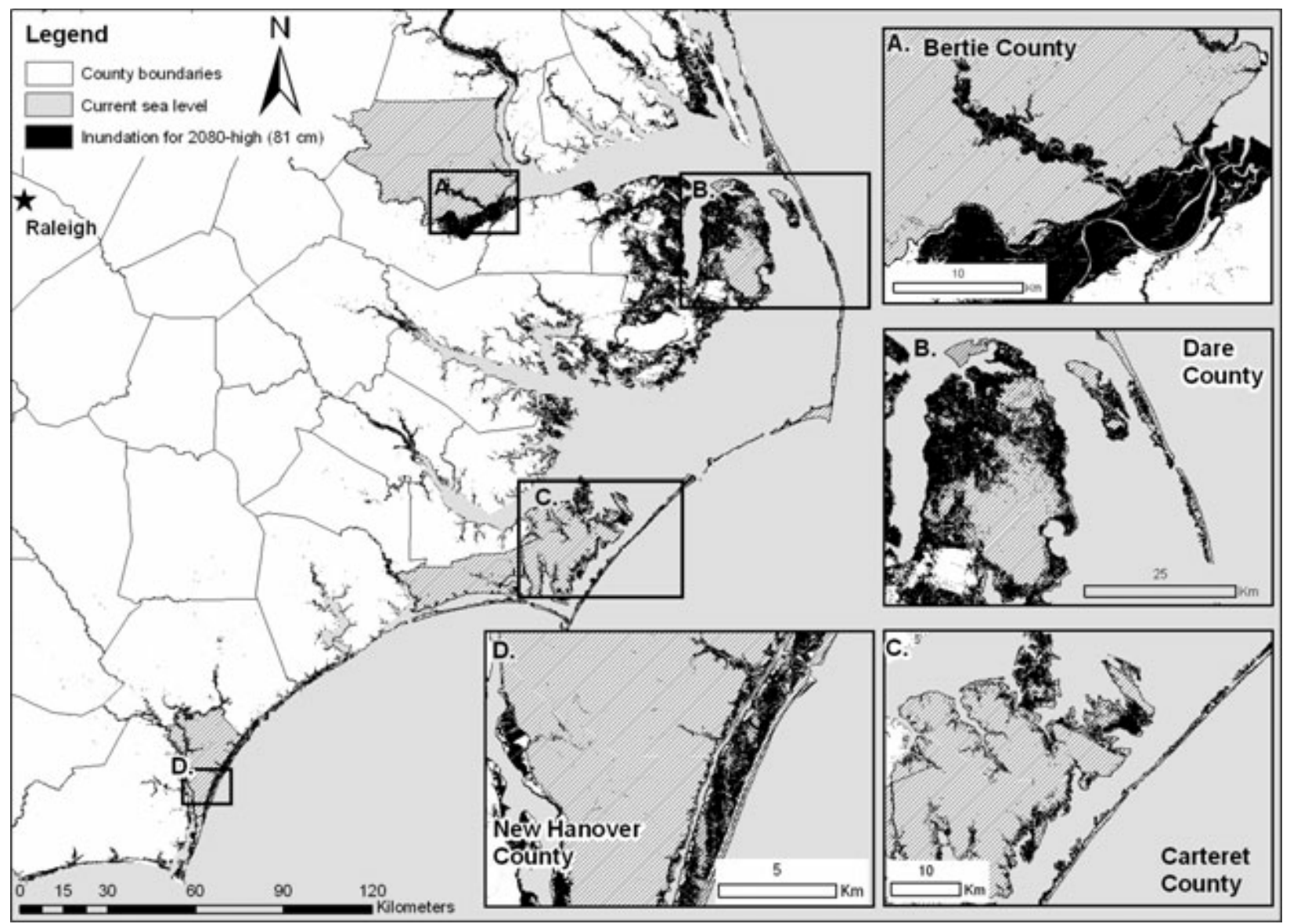

FIGURE 4: Inundation of Coastal North Carolina with the High Scenario for the Year 2080.

In general, there are very few properties below $26 \mathrm{~cm}$. In Dare County, however, there are some patches of very low elevations $(0.11 \mathrm{~m})$ that capture the 487 properties, and then very few areas between 0.11 and $0.26 \mathrm{~m}$ that have properties. 4 It represents a unique feature of the landscape on North Carolina's coast.We limit our analysis to all residential properties that locate within $1.6 \mathrm{~km}$ (1 mile) from the coastline. With an exception of Bertie County, almost all observations in Dare, Carteret, and New Hanover counties locate within $1.6 \mathrm{~km}$ from the shoreline. In Bertie County, coastal property owners may not consider the adjacent inland properties as potential substitutes. All properties at risk are within $1.6 \mathrm{~km}$ from the coastline.

\section{METHODS}

Hedonic price models have been used extensively in urban, regional, environmental, and natural resource economics as a nonmarket valuation technique. The theory of hedonic models was rationalized by Rosen (1974). It is based on the intuitive notion that the competitive market price reflects the value of attributes of the commodity. Hedonic property models use observations on property values, typically residential properties, to infer values for non-traded attributes such as distance to the shoreline or the elevation of property. We assume that the housing supply is fixed and the prices of existing 
houses are demand determined.5 The equilibrium hedonic price function is represented by

$$
R=R(s, n, e),
$$

where $R$ is the property price, which is a function of structural characteristics, $s$, neighborhood characteristics, $n$, and environmental and coastal amenities, $e$. When housing supply is taken as given, the hedonic price function emerges from competitive bidding among housing buyers. The equilibrium persists when buyers have maximized their utility, $u=U(s, n, e, y, \ldots)$, subject to a budget constraint, $m=R(s, n, e)+y$, where $U$ is a strictly concave utility function with the usual properties, $y$ is the nonhousing numeraire good, mis consumer income, and _ is the vector of variables representing demographic factors, knowledge of sea-level rise processes, and coastal management expectations. Assuming that $R(\cdot)$ is continuously differentiable, the first derivative of (1) with respect to any continuous attributes produces an estimate of the representative households' marginal willingness to pay for an additional unit of that attribute:

$$
\frac{\partial U(s, n, e, y, \alpha)}{\partial z}=\lambda \frac{\partial R(s, n, e)}{\partial z}, z=s, n, e,
$$

where _ is the marginal utility of income. There has been a tremendous increase in the availability of spatial data and spatial analysis functionality in recent years. Considerable attention has been given to examining spatial dependence in estimated hedonic equations (Brasington and Haurin, 2006; Cohen and Coughlin, 2008; Carruthers and Clark, 2010). Property sales prices tend to cluster in space because properties in a neighborhood share similar location amenities or because they have similar structural characteristics due to similar timing of construction. If the relevant spatial dependence is ignored in estimation of the hedonic price function, then the resulting estimates could be inefficient or even inconsistent, and any inference based on the estimates may result in misleading conclusions (Anselin and Bera, 1998). This study estimates the following first-order spatial error hedonic model:

$$
\begin{aligned}
\ln R & =\alpha+\sum_{i} \beta_{i} s_{i}+\sum_{j} \gamma_{j} n_{j}+\sum_{k} \phi_{k} e_{k}+\varepsilon, \\
\varepsilon & =\lambda W \varepsilon+u,
\end{aligned}
$$

where $\ln R$ is the log of assessed property value, $\alpha, \beta, \gamma$, and $\phi$ are the unknown parameters to be estimated, $\varepsilon$ is an independent random error term, _ is the spatial autoregressive coefficient, $W$ is the spatial weighting matrix, and $u$ is a vector of independent and identically distributed random error terms. This model assumes that one or more omitted variables in the hedonic equation vary spatially, and thus the error terms are spatially autocorrelated. The Ordinary Least Squares (OLS) estimator remains unbiased in this specification but is no longer efficient due to the nonspherical error covariance. Utilizing the particular structure of the error covariance implied by the 
spatial process should provide efficient estimators for the unknown parameters of the hedonic price function. Regression diagnostics based on the OLS estimation and the Lagrange multiplier (LM) test statistics indicated that the spatial error dependence is present. 6 The spatial autoregressive error models are estimated via maximum likelihood (ML). The estimation is implemented within the GeoDa v.0.9.5-i (2004) environment in conjunction with ArcView GIS 3.3 extensions.

Both reported sales prices and market-assessed values have been used in the hedonic literature as proxies for the true sales prices. Reported sales prices may not reflect the true sales prices because they may not incorporate the price adjustments in the sales negotiation process or they may be intentionally misreported (Mooney and Eisgruber, 2001). Many state statutes require that all property be valued at 100 percent of current market value for their property tax purpose. Dare County recently implemented countywide re-evaluation of property values to reflect the realmarket prices. This study uses the market-assessed values as the dependent variable in the hedonic regression because these values are highly correlated with the reported sales prices (for a limited number of the records with recent sales transactions) and result in a larger sample size for econometric analysis.

We use quadratic specifications for nondichotomous property attributes such as age of the property and total structural square footage in order to capture the diminishing marginal effect. The effect of these attributes on property values is assumed to decline as the level of these attributes increase. The primary results are robust across several alternative specifications, and the current specification provided the best overall model fit. We report the standard errors and $p$-values based upon the consistent estimator of the covariance matrix corrected for potential heteroskedasticity.

The estimated hedonic price functions are then used to simulate the property value loss for various sea-level rise scenarios. Assuming that no additional building occurs within the threatened zones with low elevation, the net loss in property values from sea-level rise in year $t$ can be represented by

$$
\text { Net } \operatorname{Loss}_{t}=\delta \cdot\left\{\mathbf{R}_{\mathrm{LOST}, t}-A_{\mathrm{LOST}, t}+\Delta \mathbf{R}_{\mathrm{INV}, t}\right\} .
$$

The first term, RLOST, $t$, is the value of lost properties in year $t$. The second term, $A L O S T, t$, is the amenity value of the lost properties in year $t$, which is purged from the total value. The property at the time of loss would not have the peak value that stems from the amenities associated with its current waterfront location. The third term, RINV,t, is the change in the value of other properties in the inventory due to a permanent change in location and the market condition of the developed area, and _ is the discount factor.

We focus on the first two terms because estimating the third term requires additional data as it depends on the risk perception and behaviors of coastal property owners (i.e. discounting and risk preference), communities, and regulatory agencies. The third term relates to adjustments induced by sea-level rise, and the impacts are relatively small compared to the first two categories. The net loss in (4) is measured by the following steps. First, the hedonic price models are estimated to predict the contribution of each attribute to the value of the property. Second, the value of risks and amenities of the lost properties are purged from the total value of the lost properties. As 
the coastal amenities as well as risks are transferred to more interior parcels rather than destroyed, several previous studies measured the value of lost property to inundation using the value of inland property (Yohe et al., 1995; Parsons and Powell, 2001). It is assumed that each lost property has the same structural characteristics but no water frontage and that it has the distance from the shoreline and the elevation evaluated at the sample mean. Third, the results are reported for no discounting as well as using a 2 percent discount rate for sensitivity analysis. 8 The choice of discount rate is crucial when assessing the economic effects of climate change (Anthoff et al., 2009). Different discount rates will lead to wide-ranging present value estimates due to the long time horizon. We use the 2 percent discount rate required by the U.S. Congressional Budget Office, which is based on the U.S. Treasury's borrowing rate (Howe, 1990).

\section{RESULTS}

The first step in this estimation process is to create a spatial weighting matrix that defines a relevant "neighborhood set" for each observation. The spatial weighting matrix determines the spatial extent of properties that may share unobserved characteristics generating spatial dependence. Using the methods suggested by Anselin and Bera (1998), we experimented with different spatial weights, and in this analysis use a spatial weighting matrix that identifies properties within $0.16 \mathrm{~km}$ (528 feet) as nonzero elements. That is, an element of the spatial weighting matrix, wij $=1$ when $i$ and $j$ are located within $0.16 \mathrm{~km}$, and $w i j=0$ otherwise. The specification of the spatial weighting matrix is based on our observations of the spatial extent that may share unobserved characteristics generating spatial dependence. We have experimented with different weighting matrices, but the primary results are largely insensitive to different weighting matrices.

The ML estimation results of the spatial hedonic models are reported in Table 3.10 The regression models controls for heterogeneity across townships using a set of binary indicators. Most structural and neighborhood variables are statistically significant at any conventional level of significance, and the coefficient signs are consistent with common findings in the hedonic literature.

Proximity to shoreline has a strong positive effect on property values. Coefficient signs for the distance to nearest shoreline, all have negative signs and are statistically significant. However, the results indicate that the coefficients for elevation are insignificant. It suggests that lower elevation of property is likely to provide easy access to coastal water, yet at the same time higher vulnerability to storm surge flooding or shoreline erosion. Again, increasing distance from the shoreline has a strong negative impact on property values. Water frontage also commands a substantial premium and raises the 
TABLE 3: ML Estimation Results for Spatial Hedonic Models

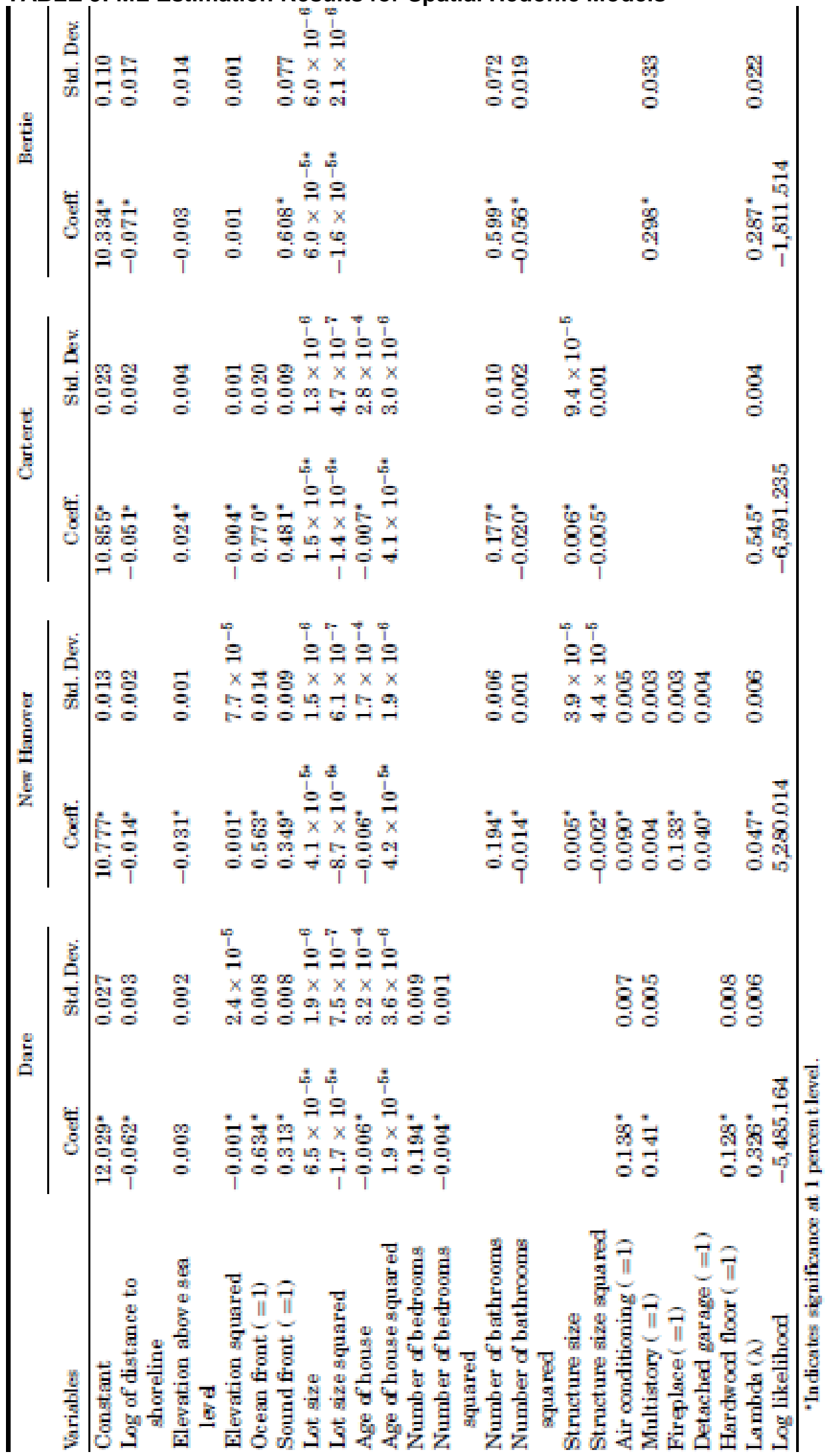


TABLE 4: : Inundation Loss of Coastal Residential Properties (without Adjustments for Inflation and Age Depreciation)

\begin{tabular}{|c|c|c|c|c|c|c|c|}
\hline & \multicolumn{7}{|c|}{ No Discounting } \\
\hline & Total & 2030-Low & 2030-Mid & 2030-High & 2080-Low & 2080-Mid & 2080-High \\
\hline Dare & $\$ 11,012.90$ & $\$ 136.01$ & $\$ 162.58$ & $\$ 196.14$ & $\$ 237.77$ & $\$ 475.78$ & $\$ 1,040.36$ \\
\hline$(n)^{4}$ & 25,232 & 487 & 580 & 699 & 849 & 1,686 & 3,737 \\
\hline$(\%)^{n+4}$ & & $1.24 \%$ & $1.48 \%$ & $1.78 \%$ & $2.16 \%$ & $4.32 \%$ & $9.45 \%$ \\
\hline New Hanover & $\$ 6,765.75$ & $\$ 4.44$ & $\$ 5.01$ & $\$ 6.35$ & $\$ 7.34$ & $\$ 10.07$ & $\$ 29.75$ \\
\hline$(n)^{*}$ & 37,414 & 14 & 16 & 22 & 24 & 33 & 117 \\
\hline$(\%)^{n}$ & & $0.07 \%$ & $0.07 \%$ & $0.09 \%$ & $0.11 \%$ & $0.15 \%$ & $0.44 \%$ \\
\hline Carteret & $\$ 4,697.57$ & $\$ 9.20$ & $\$ 10.95$ & $\$ 12.85$ & $\$ 16.19$ & $\$ 39.41$ & $\$ 113.05$ \\
\hline$(n)^{4}$ & 26,960 & 64 & 78 & 95 & 120 & 296 & 921 \\
\hline$(\%)^{n}$ & & $0.20 \%$ & $0.23 \%$ & $0.27 \%$ & $0.34 \%$ & $0.84 \%$ & $2.41 \%$ \\
\hline Bertie & $\$ 160.63$ & $\$ 0.00$ & $\$ 0.19$ & $\$ 0.28$ & $\$ 0.28$ & $\$ 0.75$ & $\$ 0.91$ \\
\hline$(n)^{*}$ & 2,460 & 0 & 2 & 4 & 4 & 12 & 16 \\
\hline \multirow[t]{3}{*}{$(\%)^{n+}$} & & $0.00 \%$ & $0.12 \%$ & $0.17 \%$ & $0.17 \%$ & $0.47 \%$ & $0.57 \%$ \\
\hline & \multicolumn{7}{|c|}{ 2\% Discounting } \\
\hline & Total & 2030-Low & 2030-Mid & 2030-High & 2080-Low & 2080-Mid & 2080-High \\
\hline Dare & $\$ 11,012.90$ & $\$ 81.28$ & $\$ 97.15$ & $\$ 117.21$ & $\$ 52.79$ & $\$ 105.63$ & $\$ 230.98$ \\
\hline$(n)^{4}$ & 25,232 & 487 & 580 & 699 & 849 & 1,686 & 3,737 \\
\hline$(\%)^{n+}$ & & $0.74 \%$ & $0.88 \%$ & $1.06 \%$ & $0.48 \%$ & $0.96 \%$ & $2.10 \%$ \\
\hline New Hanover & $\$ 6,765.75$ & $\$ 2.65$ & $\$ 2.99$ & $\$ 3.80$ & $\$ 1.63$ & $\$ 2.24$ & $\$ 6.61$ \\
\hline$(n)^{4}$ & 37,414 & 14 & 16 & 22 & 24 & 33 & 117 \\
\hline$(\%)^{n+k}$ & & $0.04 \%$ & $0.04 \%$ & $0.06 \%$ & $0.02 \%$ & $0.03 \%$ & $0.10 \%$ \\
\hline Carteret & $\$ 4,697.57$ & $\$ 5.50$ & $\$ 6.55$ & $\$ 7.68$ & $\$ 3.60$ & $\$ 8.75$ & $\$ 25.10$ \\
\hline$(n)^{4}$ & 26,960 & 64 & 78 & 95 & 120 & 296 & 921 \\
\hline$(\%)^{n *}$ & & $0.12 \%$ & $0.14 \%$ & $0.16 \%$ & $0.08 \%$ & $0.19 \%$ & $0.53 \%$ \\
\hline Bertie & $\$ 160.63$ & $\$ 0.00$ & $\$ 0.12$ & $\$ 0.17$ & $\$ 0.06$ & $\$ 0.17$ & $\$ 0.20$ \\
\hline$(n)^{4}$ & 2,460 & 0 & 2 & 4 & 4 & 12 & 16 \\
\hline$(\%)^{n+}$ & & $0.00 \%$ & $0.07 \%$ & $0.10 \%$ & $0.04 \%$ & $0.10 \%$ & $0.13 \%$ \\
\hline
\end{tabular}

property values between 56.3 percent (New Hanover) and 77.0 percent (Carteret) for ocean frontage and between 31.3 percent (Dare) and 60.8 percent (Bertie) for estuarine water frontage. Milon et al. (1984) estimated a large positive value from being close to the shore. They found that property values declined 36 percent in moving 500 feet from the Gulf of Mexico. Other studies have also found positive values for water proximity (Shabman and Bertelson, 1979; Earnhart, 2001).

The simulation results under different sea-level rise scenarios are reported in Table 4. A zero discount rate and a 2 percent discount rate are used to provide the present value of the residential property value loss. In addition, we provide an alternative set of the estimates based on the adjustments for age at the time of loss and inflation in Table 5. An adjustment was made for property values because age has a negative effect and the property loss occurs in the future.11 The predicted value of each lost property is inflated to 2030 or 2080.12 Given our rather strong assumptions such as no adaptation or mitigation 
TABLE 5: Inundation Loss of Coastal Residential Properties (with Adjustments for Inflation and Age Depreciation)

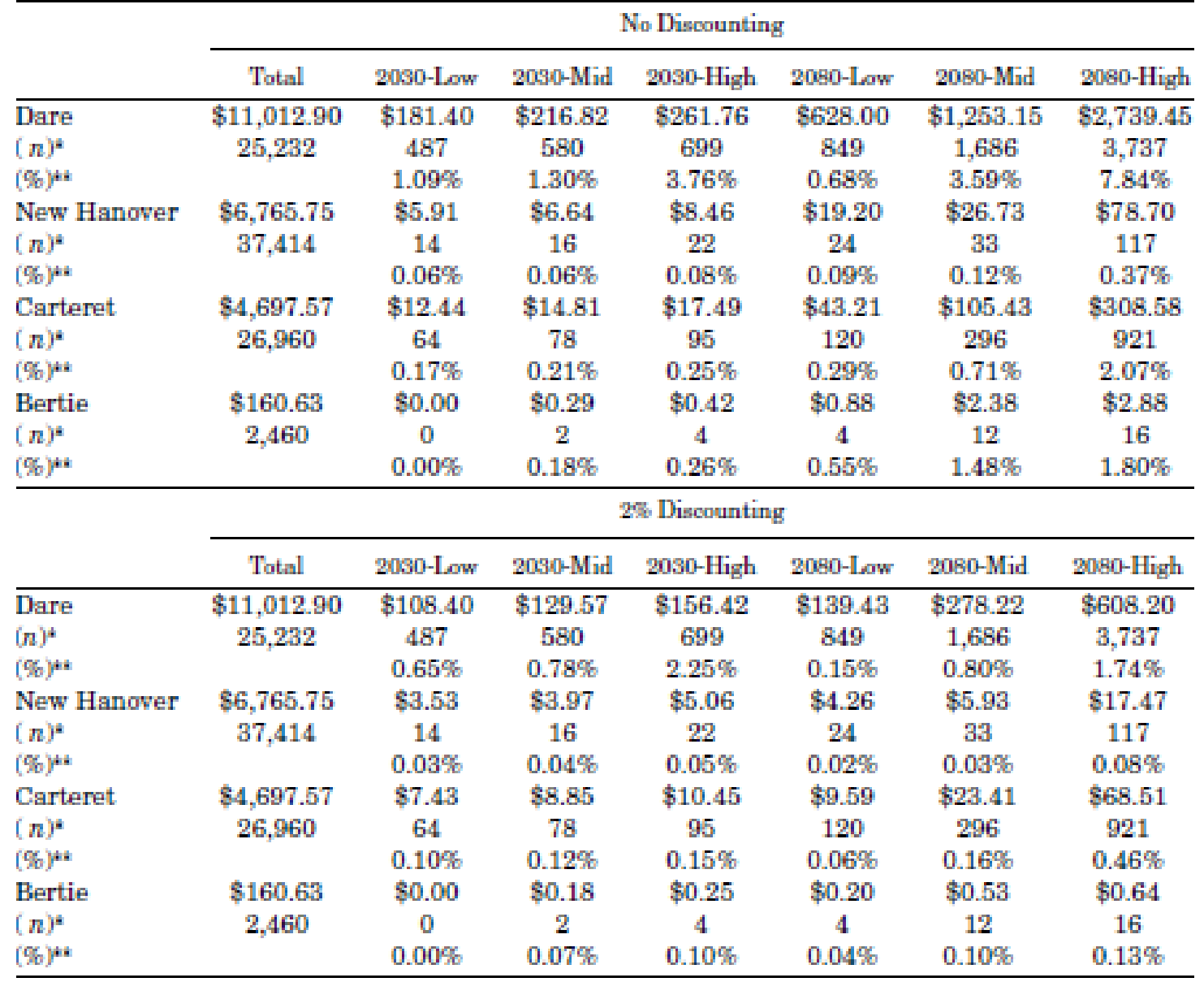

Notes: Dollars are measured in million. "The number of inundated properties. "The percentage of the total property values.

policy and no new housing development in the future, we focus on the results from Table 4, which appear to be the best snapshot of the impact at the present value of the properties.

For Dare County, a total of 25,232 residential properties are used in the analysis with the total assessed value of $\$ 11$ billion. Depending on the sea-level rise scenarios, the number of residential properties at the risk of inundation ranges between 487 (2030Low) and 3737 (2080-High). Without discounting, the residential property value loss in Dare County ranges from $\$ 136$ million (1.24 percent of the total assessed value) to $\$ 1040$ million (9.45 percent of the total assessed value). Based on the 2 percent discount rate, the estimated loss ranges from $\$ 81$ million ( 0.74 percent) to $\$ 231$ million (2.10 percent). The results indicate that Dare County has the most significant impact from sea-level rise among the North Carolina coastal counties.

For New Hanover County, a total of 37,414 residential properties are used in the analysis with the total assessed value of $\$ 6.8$ billion. Depending on the sea-level rise scenarios, the number of residential properties at the risk of inundation ranges between 14 (2030-Low) and 117 (2080-High).Without discounting, the residential property value loss in New Hanover County ranges from \$4.4million (0.07 percent of the total assessed 
value) to $\$ 29.8$ million ( 0.44 percent of the total assessed value). Based on the 2 percent discount rate, the estimated loss ranges from \$2.7 million (0.04 percent) to \$6.6 million ( 0.10 percent). The results indicate that New Hanover County has a relatively insignificant impact from sea-level rise among the North Carolina coastal counties.

For Carteret County, a total of 26,960 residential properties are used in the analysis with the total assessed value of $\$ 4.7$ billion. Depending on the sea-level rise scenarios, the number of residential properties at the risk of inundation ranges between 64 (2030- Low) and 921 (2080-High). Without discounting, the residential property value loss in Carteret County ranges from $\$ 9.2$ million (0.20 percent of the total assessed value) to $\$ 113.1$ million (2.41 percent of the total assessed value). Based on the 2 percent discount rate, the estimated loss ranges from $\$ 5.5$ million (0.12 percent) to $\$ 25.1$ million (0.53 percent). The results indicate that Carteret County has a relatively significant impact from sea-level rise.

For Bertie County, a total of 2,460 residential properties are used in the analysis with the total assessed value of $\$ 160$ million. Depending on the sea-level rise scenarios, the number of residential properties at the risk of inundation ranges between 0 (2030Low) and 16 (2080-High). Without discounting, the residential property value loss in Bertie County ranges from $\$ 0$ ( 0.00 percent of the total assessed value) to $\$ 0.91$ million ( 0.57 percent of the total assessed value). Based on the 2 percent discount rate, the estimated loss ranges from $\$ 0$ ( 0.00 percent) to $\$ 0.2$ million ( 0.13 percent). The loss of residential property values in Bertie County is relatively smaller than those of the other counties discussed above.

Our estimates are in line with the findings from the previous studies. Michael (2007) focused on three communities on the Chesapeake Bay and found that the inundation loss of improved residential property for the 3-foot scenario ranged from $\$ 0.4$ million (Shadyside) to $\$ 2.7$ million (Hooperslsland) using a 2 percent discount rate. Based on historic erosion rates, Parsons and Powell (2001) estimated that the loss of coastal retreat over the next 50 years is about $\$ 291$ million for the entire Delaware coastline using a 3 percent discount rate. Based on the 2080-High scenario, our estimates ranged from $\$ 0.2$ million (Bertie County) to $\$ 231$ million (Dare County) with a 2 percent discount rate. Caution is needed for the direct comparison of the estimates because the level of development and the area coverage vary across these studies.

\section{DISCUSSION}

Economic analysis of climate change and sea-level rise should compare the benefits and costs of alternative policies. The North Carolina coast is one of the most vulnerable to sea-level rise in the United States. One of the purposes of this study is to estimate some previously unknown costs of sea-level rise in this vulnerable area to fill in an important knowledge gap. Once these benefits and costs are better known, coastal management policy can address them with various policies. When and where the benefits of adaptation exceed the costs, local communities should pursue policy such as beach nourishment, seawalls or retreat. Even here, estimates of benefits and costs are important in determining the type of policy to pursue. Beach retreat is likely the most viable long-term strategy against sea-level rise. But in the short run, its costs are much higher. In our analysis, beach retreat would be less attractive in already population 
dense counties. In counties with less population density, beach retreat may be a more attractive option. When the benefits of adaptation are less than the costs, national governments should consider the pursuit of climate change mitigation policies such as a carbon tax, cap-and-trade, renewable energy portfolio standards, and energy efficiency standards. In the long run, reductions in carbon emissions would slow the rate of sealevel rise and avoid some of the costs of sea-level rise on coastal property owners.

In this study, we estimate the impact of sea-level rise on coastal real estate in four coastal counties including the three most populous (Dare, New Hanover, and Carteret) on the North Carolina coast. Our results indicate that the magnitude of the impacts depends on the geographic location and the level of development in the areas. The northern part of the North Carolina coastline is comparatively more vulnerable to the effect of sea-level rise than the southern part. Low-lying and heavily developed areas in the northern coastline of North Carolina are especially at high risk from sealevel rise.

Care must be taken with the interpretation of the results. The current study focuses on the loss of property value from permanent inundation. Temporary inundation caused by high tides and storms occurs much sooner in time than permanent flooding, and the costs associated with it can be quite large relative to those associated with permanent flooding. Measuring the impacts of temporary flooding requires additional data such as the distribution of the partial damage extents due to storm surge, frequency and intensity of storms, and timing of storms. Flood insurance may change the estimated loss, although the insurance covers only the structures (not the land) and does not cover the loss due to sea-level rise. The current flood insurance coverage is limited to $\$ 250,000$ for a single-family residence.

It is important to point out that a large portion of undeveloped land in coastal North Carolina is wetlands that provide a wide range of services such as habitat for fish and wildlife, flood protection, water quality improvement, opportunities for recreation, education and research, and aesthetic values. These functions and services are economically and ecologically valuable. Since these values are unlikely to be fully reflected in the private property values, the estimated impacts in this study provide only a limited measure of total economic costs associated with sea-level rise. Our impact estimates do not address other important nonresidential property such as marinas or industrial facilities due to data limitation.

In addition, this study does not consider the adaptation that coastal communities and property owners undertake as they observe sea-level rise over time. They may decide to relocate their communities in response to sea-level rise or pursue beach nourishment or hardening. The property value impacts can be mitigated by the mining and deposition of replacement sand on eroded beaches and shorelines. There might be additional costs associated with increased distance to the shoreline for new development. The value of lost public infrastructure is another component that is not included in the current study, although it is likely to be small especially in the rural areas. Although it is not possible at this time to estimate the impacts of sea-level rise on lost public infrastructure, Parsons and Powell (2001) shed some light on the economic impacts on this sector. Parsons and Powell (2001) assessed that public infrastructure losses and proximity losses due to beach retreat in Delaware are likely to be a small fraction of the total over the next 50 years as the vast majority of developed land in 
coastal Delaware is residential housing. Although a comprehensive cost-benefit analysis is beyond the scope of this study, these estimates could provide valuable information for policymakers as they consider various policy options to mitigate the impact of climate change. Hopefully, this study will stimulate future research on the comprehensive benefit-cost analysis of climate change policy to inform if such policy could be justified from an economic efficiency perspective.

\section{References}

Anselin, Luc and Anil Bera. 1998. "Spatial Dependence in Linear Regression Models with an Introduction to Spatial Econometrics," in Aman Ullah, and David E. A. Giles (eds.), Handbook of Applied Economic Statistics.

CRC Press.

Anthoff, David, Richard S. J. Tol, and Gary W. Yohe. 2009. "Discounting for Climate Change," Economics: The Open-Access Open-Assessment E-Journal, 3, 2009-2024

Brasington, David and Don Haurin. 2006. "Educational Outcomes and House Values: A Test of the value added Approach," Journal of Regional Science, 46, 245-268.

Carruthers, John I. and David E. Clark. "Valuing Environmental Quality: A Space-Based Strategy," Journal of Regional Science, 50 (4), 801-832.

Cline, William R. 1992. The Economics of Global Warming, Washington, D.C.: Institute for International Economics.

Cohen, Jeffrey P. and Cletus C. Coughlin. 2008. "Spatial HedonicModels of Airport Noise, Proximity, and Housing Prices," Journal of Regional Science, 48, 859-878.

Darwin, Roy and Richard Tol. 2001. "Estimates of the Economic Effects of Sea Level Rise," Environmental and

Resource Economics, 19, 113-129. 
Earnhart, Dietrich. 2001. "Combining Revealed and Stated Preference Methods to Value Environmental Amenities at Residential Locations," Land Economics, 77, 12-29.

Heinz Center for Science, Economics and Environment. 2000. "Evaluation of Erosion Hazards Summary," prepared for Federal Emergency Management Agency. Available at http://www.heinzctr.org/publications/PDF/erosnrpt.pdf. Last accessed: November 2010.

Howe, Charles W. 1990. "The Social Discount Rate," Journal of Environmental Economics and Management, 18(2), S1-S2.

Intergovernmental Panel on Climate Change (IPCC). 2007. Climate Change 2007: The Physical Science Basis. New York, NY: United Nations.

Mastrandrea, Michael D. and Stephen H. Schneider. 2004. "Probabilistic Integrated Assessment of 'Dangerous' Climate Change," Science, 304, 571-575.

McKenzie, Russell and John Levendis. 2010. "Flood Hazards and Urban Housing Markets: The Effects of Hurricane Katrina on New Orleans," Journal of Real Estate Finance and Economics, 40, 62-76.

Michael, Jeffrey A. 2007. "Episodic Flooding and the Cost of Sea-Level Rise," Ecological Economics, 63, 149-159.

Milon, J. Walter, Jonathan Gressel, and David Mulkey. 1984. "Hedonic Amenity Valuation and Functional Form Specification," Land Economics, 60, 378-387.

Mooney, Sian and Ludwig M. Eisgruber. 2001. "The Influence of Riparian Protection Measures on Residential Property Values: The Case of the Oregon Plan for Salmon and Watersheds," Journal of Real Estate Finance and Economics, 22(2), 273-286.

Moorhead, Kevin K. and Mark M. Brinson. 1995. "Response of Wetlands to Rising Sealevel in the Lower Coastal Plain of North Carolina," Ecological Applications, 5, 261-271.

National Oceanic and Atmospheric Administration. 2005. "Population Trends along the Coastal United States: 1980-2008," U.S. Department of Commerce.

Palmquist, Raymond B. 2004. "Property Value Models," in K-G Maler and J. Vincent (eds.), Handbook of Environmental Economics, Vol. 2. North Holland.

Parsons, George R. and Michael Powell. 2001. "Measuring the Cost of Beach Retreat," Coastal Management, 29, 91-103.

Pfeffer, W., J. Harper, and S. O'Neel. 2008. "Kinematic Constraints on Glacier Contributions to 21st-Century Sea-Level Rise," Science, 321, 1340-1343. 
Poulter, B. and P.N. Halpin. 2008. "Raster Modelling of Coastal Flooding from Sea Level Rise," International Journal of Geographical Information Science, 22(2), 167-182.

Rosen, Sherwin. 1974. "Hedonic Prices and Implicit Markets: Product Differentiation in Pure Competition," Journal of Political Economy, 82(1), 34-55.

Shabman, Leonard and Michael K. Bertelson. 1979. "The Use of Development Value Estimates for Coastal Wetland Permit Decisions," Land Economics, 55, 213-222.

Titus, James G. 1992. "The Cost of Climate Change to the United States," in Shyamal K. Majumdar, L.S. Kalkstein, B. Yarnal, E.W. Miller, and L.M. Rosenfeld (eds.), Global Climate Change: Implications, Challenges, and Mitigation Measures, Pennsylvania: Pennsylvania Academy of Science.

Titus, James G. and Charlie Richman. 2001. "Maps of Lands Vulnerable to Sea-level Rise: Modeled Elevations along the US Atlantic and Gulf coasts," Climate Research, 18, 205-228.

Tushingham, A.M. and W.R. Peltier. 1991. "A New Global Model of Late Pleistocene Deglaciation Based upon Geophysical Predictions of Post Glacial Relative Sea-level Change," Journal of Geophysical Research, 96, 4497-4523.

West, J. Jason, Mitchell J. Small, and Hadi Dowlatabadi. 2001. "Storms, Investor Decisions, and the Economic Impacts of Sea Level Rise," Climatic Change, 48, 317342.

Yohe, Gary, James Neumann and Holly Ameden. 1995. "Assessing the Economic Cost of Greenhouse-induced Sea Level Rise: Methods and Application in Support of a National Survey," Journal of Environmental Economics and Management, 29, S78-S97.

Yohe, Gary, James Neumann, Patrick Marshall, and Holly Ameden. 1996. "The Economic Cost of Greenhouse Induced Sea Level Rise for Developed Property in the United States," Climatic Change, 32, 387-410.

Yohe, Gary, James Neumann, and Patrick Marshall. 1999. "The Economic Damage Induced by Sea Level Rise in the United States," in R. Mendelsohn and J. Neumann (eds.), The Impact of Climate Change on the United States Economy. Cambridge University Press. 